\title{
Debt and welfare in economies with land
}

\author{
Nikolaos Kokonas $^{1}$ • Herakles Polemarchakis ${ }^{2}$
}

Received: 26 August 2014 / Accepted: 7 June 2016 / Published online: 1 July 2016

(C) The Author(s) 2016. This article is published with open access at Springerlink.com

\begin{abstract}
In a stochastic economy of overlapping generations subject to uninsurable risks, debt can implement Pareto improvements in welfare. This is the case even in the presence of long-lived assets and no short sales.
\end{abstract}

Keywords Long-lived assets · Optimality · Overlapping generations

JEL Classification D52 - D61

\section{Introduction}

Sovereign debt has given rise to two branches of research; more or less independent, and cross-effects remain to be considered. One was initiated by Bulow and Rogoff (1989), who focused on incentives for default; here we take our cue from Diamond (1965), who argued that debt can restore optimality when, as in economies of overlapping generations, the market fails to guarantee it. Alternatively, long-lived assets suffice to restore optimality under certainty or compete markets in elementary securities, and debt becomes unnecessary, if not unsustainable, because of transversality. And Demange (2002) argued that this is also the case even with uninsurable risks in an

Nikolaos Kokonas

n.kokonas@bath.ac.uk

Herakles Polemarchakis

h.polemarchakis@warwick.ac.uk

1 Department of Economics, University of Bath, Claverton Down Rd, Bath, North East Somerset BA2 7AY, UK

2 Department of Economics, University of Warwick, Coventry CV4 7AL, UK 
incomplete asset market. Evidently, then, it is constrained optimality that is at stake. Our argument is that constrained optimality applies only in the case of two-period life spans and one, aggregate, commodity at each date: in economies with a richer commodity or demographic structure constrained optimality may fail and debt can implement Pareto improvements in welfare.

More precisely, long-lived assets, land or "Lucas-trees", restore optimality in economies that extend over an infinite time-horizon. Wilson (1981) developed the argument for economies under certainty, and Santos and Woodford (1997) extended the argument to economies under uncertainty as long as the asset market is complete.

The possible failure of optimality has been studied extensively and is well understood. It derives from the failure of aggregate valuation or, equivalently, an aggregate budget constraint that obtains when the real rate of interest falls short of the rate of growth of output. Samuelson (1958) and Diamond (1965) first argued that aggregate debt or, equivalently, pay-as-you-go social security, may implement optimal allocations, low interest rates notwithstanding. Cass (1972) gave a condition, weaker than aggregate valuation, that is necessary and sufficient for a price path to support a Pareto optimal allocation.

In the presence of uninsurable risks, the optimality properties of competitive allocations are problematic even in finite economies. Not only do competitive allocations typically fail to be optimal, which is not surprising or even relevant, but, typically, they fail to be even constrained optimal: competitive markets fail to make optimal use of the restricted reallocations of risks that fundamentals allow. Geanakoplos and Polemarchakis (1986) showed that, typically, reallocations of the existing assets implement Pareto improvements; Carvajal and Polemarchakis (2011) extended the argument to economies with (purely) idiosyncratic risks. Importantly, constrained suboptimality occurs with multiple commodities or periods of economic activity, and it derives from the variation in relative prices that competitive markets fail to internalize.

Demange (2002) demonstrated an important and surprising result: in an economy of overlapping generations with life-spans of two periods and one, aggregate commodity at each period, long lived assets traded subject to a ban on short sales restore the constrained optimality of competitive allocations in the presence of uninsurable risks: there is no intervention that respects both the prevailing restrictions on risk sharing and the ban on short sales and implements a Pareto improvement. Here, we give a series of examples that demonstrate the dependance of constrained optimality on the restriction to life-spans of two periods and a single commodity. With multiple commodities or multiple periods in the economic life-time of generations, constrained suboptimality may arise.

Lucas and Stokey (1983) and Angeletos (2002) considered optimal fiscal policy under uncertainty, while Diamond and Geanakoplos (2003) and Dutta et al. (2000) characterized optimal financial policies for social security. The constrained suboptimality of competitive allocations provides a foundation for intervention. Here, with debt along with long-lived assets, aggregate debt policy implements Pareto improvements. 


\section{Land}

The economy is stationary, of overlapping generations with life-spans of three periods. Each generation consists of a continuum, of mass 1, of initially identical individuals. There is one perishable commodity at each date. Individuals receive a deterministic endowment, $e^{y}$, when young, a stochastic endowment, $e_{s}^{m}$, when middle-aged, and, again, a deterministic endowment, $e^{o}$, when old. Personal states, $s$, occur with probability $\pi_{s}$; there is no aggregate risk. Land, in aggregate supply 1, produces a constant dividend, $f$. The cardinal utility index, $u$, satisfies standard curvature, smoothness and boundary assumptions. Consumption is $c$, and it is numéraire; holdings of land are $y$ and the price of land is $q$. Time commences at $t=0$; we omit the subscript, $t$, that indicates dates, when no ambiguity arises.

The decision problem of an individual is

$$
\begin{aligned}
& \max U=\left[u\left(c^{y}\right)+E\left[u\left(c_{s}^{m}\right)\right]+E\left[u\left(c_{s}^{o}\right)\right]\right], \\
& \text { s.t. } \\
& c^{y}+q y^{y}=e^{y}, \\
& c_{s}^{m}+q y_{s}^{m}=e_{s}^{m}+(f+q) y^{y}, \\
& c_{s}^{o}=e^{o}+(f+q) y_{s}^{m}
\end{aligned}
$$

first order conditions are

$$
\begin{aligned}
\frac{q}{f+q} u^{\prime}\left(c^{y}\right) & =E\left[u^{\prime}\left(c_{s}^{m}\right)\right], \\
\frac{q}{f+q} & =\frac{u^{\prime}\left(c_{s}^{o}\right)}{u^{\prime}\left(c_{s}^{m}\right)} .
\end{aligned}
$$

Equilibrium in the asset markets requires that

$$
y^{y}+E\left[y_{s}^{m}\right]=1
$$

the expectation operator aggregates land holdings of middle-aged individuals. Evidently, middle-aged and old individuals at the initial date, $t=0$, with appropriate utility functions and asset holdings, implement a stationary equilibrium when activity does not extend to the infinite past.

We shall argue that there are robust situations in which a fiscal authority can implement a Pareto improvement relative to the stationary competitive equilibrium allocation; this, without short sales either before or after the intervention: $y^{y}, y_{s}^{m}>0$.

The policy instrument is an exogenous specification of investment in land by individuals when young: $y^{y}$. Subsequently, individuals trade in competitive markets. In the absence of aggregate risk, and since individuals are identical at the beginning of their lives, the intervention does not go beyond allocations a market could implement. 
At a stationary competitive equilibrium

$$
\begin{aligned}
& \frac{q}{f+q} u^{\prime}\left(e^{y}-q y^{y}\right)=E\left[u^{\prime}\left(e_{s}^{m}+(f+q) y^{y}-q y_{s}^{m}\right)\right], \\
& \frac{q}{f+q}=\frac{u^{\prime}\left(e^{o}+(f+q) y_{s}^{m}\right)}{u^{\prime}\left(e_{s}^{m}+(f+q) y^{y}-q y_{s}^{m}\right)}, \text { and } \\
& y^{y}+E\left[y_{s}^{m}\right]=1 .
\end{aligned}
$$

To complete the characterisation of a stationary equilibrium we need to specify appropriate initial conditions. There exists an initial old generation with preferences defined, without loss of generality, by $U_{0}^{o}\left(c_{0}^{o}\right)=c_{0}^{o}$, and aggregate endowment and holdings of land as the old generation at the stationary equilibrium; and groups, $s$, of initial middle-aged generations, of size $\pi_{s}$, with life-spans of two periods, preferences $U_{s}^{m}\left(c_{s}^{m}, c_{s}^{o}\right)=u\left(c_{s}^{m}\right)+u\left(c_{s}^{o}\right)$ and aggregate endowments and initial holdings of land as all future middle-aged generations.

We fix $u(c)=\log (c)$ and endowments $e_{s}^{m}=e^{m}+\epsilon_{s}>0$, where $e^{m}>0$, $E_{\pi}\left(\epsilon_{s}\right)=0$, and $e^{o}=0$; the latter guarantees that the middle-aged cohort never short-sell land, while parameter values shall be such that, at the stationary equilibrium, young generations also do not short-sell.

An economy is specified by the parameters $\left(f, e^{y}, e^{m}, \ldots, \pi_{s}, \ldots \epsilon_{s}, \ldots\right)$, and a property is robust if it obtains for an open set of economies.

At all periods, a fiscal authority dictates investment in land, $\tilde{y}_{t}^{y}$, by young individuals; in addition, it redistributes wealth, but, only at $t=0$. Redistribution or transfers at $t=0$ are $\tau$. Young generations have no discretion on their consumption or savings. On the other hand, middle-aged generations do: they allocate consumption-saving optimally given the land holdings specified by the fiscal authority when young.

We do not restrict attention to stationary interventions, and, as a consequence, we specify $t$ when necessary. Nevertheless, for a Pareto improvement, it suffices for the fiscal authority to set $\left\{\widetilde{y}_{t}^{y}\right\}_{t=0}^{\infty}$, with $\tilde{y}_{t}^{y}>0$, and $\tilde{y}_{t}^{y}=\tilde{y}^{y}$, for $t \geqslant 1:$ the intervention is stationary after the initial date.

From the first order condition of the middle-aged at $t \geqslant 1$,

$$
\frac{\widetilde{q}_{t}}{f+\widetilde{q}_{t+1}}=\frac{e_{s}^{m}+\left(f+\widetilde{q}_{t}\right) \widetilde{y}_{t-1}^{y}-\widetilde{q}_{t} \widetilde{y}_{t, s}^{m}}{\left(f+\widetilde{q}_{t+1}\right) \widetilde{y}_{t, s}^{m}}
$$

or

$$
\widetilde{y}_{t, s}^{m}=\frac{e_{s}^{m}+\left(f+\widetilde{q}_{t}\right) \widetilde{y}_{t-1}^{y}}{2 \widetilde{q}_{t}} .
$$

We substitute $\widetilde{y}_{t, s}^{m}$ into the market clearing for land, $E\left[\widetilde{y}_{t, s}^{m}\right]=1-\tilde{y}_{t}^{y}$, to solve for equilibrium prices,

$$
\widetilde{q}_{t}=\frac{e^{m}+f \widetilde{y}_{t-1}^{y}}{2\left(1-\tilde{y}_{t}^{y}\right)-\tilde{y}_{t-1}^{y}} .
$$


Since we focus on stationary interventions after the initial date, asset prices at $t=1$ simplify as

$$
\widetilde{q}_{1}=\frac{e^{m}+f \widetilde{y}_{0}^{y}}{2\left(1-\tilde{y}^{y}\right)-\widetilde{y}_{0}^{y}}
$$

and at $t \geqslant 2$ as

$$
\widetilde{q}=\frac{e^{m}+f \widetilde{y}^{y}}{2\left(1-\widetilde{y}^{y}\right)-\widetilde{y}^{y}}
$$

For $t=0$, the first order conditions of initial middle-aged rewrite as

$$
\frac{\widetilde{q}_{0}}{f+\widetilde{q}_{1}}=\frac{e_{s}^{m}+\tau_{0, s}^{m}+\left(f+\widetilde{q}_{0}\right) y^{y}-\widetilde{q}_{0} \widetilde{y}_{0, s}^{m}}{\left(f+\widetilde{q}_{1}\right) \widetilde{y}_{0, s}^{m}}
$$

or

$$
\widetilde{y}_{0, s}^{m}=\frac{e_{s}^{m}+\tau_{0, s}^{m}+\left(f+\widetilde{q}_{0}\right) y^{y}}{2 \widetilde{q}_{0}}
$$

$y^{y}$ are initial asset holdings and $\tau_{0, s}^{m}$ are transfers they get from the fiscal authority. From period zero asset market clearing,

$$
\widetilde{q}_{0}=\frac{e^{m}+E\left[\tau_{0, s}^{m}\right]+f y^{y}}{2\left(1-\tilde{y}_{0}^{y}\right)-y^{y}} .
$$

The dynamics of asset prices ${ }^{1}$ are $\left\{\widetilde{q}_{t}\right\}_{t=0}^{\infty}$, with $\widetilde{q}_{t}=\widetilde{q}$, for $t \geqslant 2$ : asset prices are stationary after $t=1$.

We shall demonstrate that a Pareto improvement obtains for $\widetilde{q}_{1}>q$ and $\widetilde{q}<q$. Moreover, we restrict the analysis to marginal changes of land holdings and date 0 transfers that translate to marginal changes of prices, allocations and utilities. We outline the construction of a Pareto improving intervention; a complete derivation is in the Appendix. For simplicity, we use the notation $u(c)$, keeping in mind that $u(c)=\log (c)$.

Generations $t \geqslant 2$ are better-off if and only if

$$
\frac{\mathrm{d} U_{t}}{u^{\prime}\left(c^{y}\right)}=-\mathrm{d} q\left(y^{y}\left(1-\frac{q}{f+q}\right)+\left(1-\frac{q}{f+q}\right) E\left[\frac{u^{\prime}\left(c_{s}^{m}\right)}{u^{\prime}\left(c^{y}\right)} y_{s}^{m}\right]\right)>0
$$

$\mathrm{d} q$ is the marginal change of asset prices at $t \geqslant 2$ relative to the competitive equilibrium. The term that multiplies $\mathrm{d} q$ in (1) is always positive at a stationary equilibrium

${ }^{1}$ The assumption of $e^{o}=0$ simplifies the dynamics of asset prices. In particular, the asset price at $t$ is not a function of the asset price at $(t+1)$ but, instead, is pinned down only by the land holdings of young individuals. Our results extend to the case where $e^{o}>0$. 
that is characterised by no short sales of land. Generations $t \geqslant 2$ are better off if and only if $\mathrm{d} q<0(\widetilde{q}<q)$ : asset prices at $t \geqslant 2$ should be lower than at the stationary competitive equilibrium. The fiscal authority can decrease investment in land by young individuals after the initial date to make $\mathrm{d} q<0$ and, as a result, make generations $t \geqslant 2$ better off.

For $t=0$, and since, then (and only then) the fiscal authority can redistribute revenue, for a Pareto improvement it suffices that

$$
\mathrm{d} c_{0}^{o}+E\left[\frac{\mathrm{d} U_{0, s}^{m}}{u^{\prime}\left(c_{s}^{m}\right)}\right]+\frac{\mathrm{d} U_{0}}{u^{\prime}\left(c^{y}\right)}>0
$$

or, equivalently,

$$
\mathrm{d} q_{1}\left(\frac{q}{f+q}-E\left[\frac{u^{\prime}\left(c_{s}^{m}\right)}{u^{\prime}\left(c^{y}\right)} y_{s}^{m}\right]\right)+\mathrm{d} q \frac{q}{f+q} E\left[\frac{u^{\prime}\left(c_{s}^{m}\right)}{u^{\prime}\left(c^{y}\right)} y_{s}^{m}\right]>0
$$

Expression (2) depends only on the marginal change of asset prices at $t=1, \mathrm{~d} q_{1}$, and at $t=2, \mathrm{~d} q$; the marginal change of period zero asset price cancels out and transfers (redistribution of revenue) add up to zero. The terms multiplying $\mathrm{d} q_{1}$ and $\mathrm{d} q$ are positive at the stationary equilibrium. Since we require $\mathrm{d} q<0$, a necessary condition for (2) to be satisfied is $\mathrm{d} q_{1}>0\left(\widetilde{q}_{1}>q\right)$ : asset prices at $t=1$ should be higher than at the competitive equilibrium. The fiscal authority can increase investment in land by young individuals at the initial date to satisfy (2) and, with appropriate redistribution, make everyone at $t=0$ better off.

Finally, the generation $t=1$ is better-off if and only if

$$
\frac{\mathrm{d} U_{1}}{u^{\prime}\left(c^{y}\right)}=-\mathrm{d} q\left(-y^{y}\left(\frac{q}{f+q}-\frac{\mathrm{d} q_{1}}{\mathrm{~d} q}\right)+\left(1-\frac{q}{f+q}\right) E\left[\frac{u^{\prime}\left(c_{s}^{m}\right)}{u^{\prime}\left(c^{y}\right)} y_{s}^{m}\right]\right)>0 .
$$

Since we require $\mathrm{d} q<0$, the generation $t=1$ is better-off if and only if the term inside the big parenthesis in (3) (that multiplies $-\mathrm{d} q$ ) is positive or, equivalently,

$$
\left(1-\frac{q}{f+q}\right) E\left[\frac{u^{\prime}\left(c_{s}^{m}\right)}{u^{\prime}\left(c^{y}\right)} y_{s}^{m}\right]>y^{y}\left(\frac{q}{f+q}-\frac{\mathrm{d} q_{1}}{\mathrm{~d} q}\right) .
$$

To demonstrate that (4) is satisfied and as a consequence generation $t=1$ is better off, it is convenient to combine (2) and (4) as 


$$
\begin{aligned}
& \underbrace{\left(1-\frac{q}{f+q}\right) E\left[\frac{u^{\prime}\left(c_{s}^{m}\right)}{u^{\prime}\left(c^{y}\right)} y_{s}^{m}\right]}_{=A}>\underbrace{y^{y}\left(\frac{q}{f+q}-\frac{\mathrm{d} q_{1}}{\mathrm{~d} q}\right)}_{=B} \\
& >\underbrace{y^{y}\left(\frac{q}{f+q}+\frac{\frac{q}{f+q} E\left[\frac{u^{\prime}\left(c_{s}^{m}\right)}{u^{\prime}\left(c^{y}\right)} y_{s}^{m}\right]}{\frac{q}{f+q}-E\left[\frac{u^{\prime}\left(c_{s}^{m}\right)}{u^{\prime}\left(c^{y}\right)} y_{s}^{m}\right]}\right)}_{=\Gamma} .
\end{aligned}
$$

$A>B$ is identical to (4), while $B>\Gamma$ is equivalent to (2). $A>\Gamma$ is a property of the stationary competitive equilibrium; $A, \Gamma$ do not depend on marginal changes of asset prices, but, rather, on the characteristics of the stationary competitive equilibrium. There exist interventions at the initial date such that $B>\Gamma$, as argued earlier, and, in addition, $B$ arbitrarily close to $\Gamma$. Since $A>\Gamma$, there exist interventions such that $A>B$ and generation $t=1$ is better off. This completes the argument.

The intuition behind the constrained suboptimality result can be best understood if we focus on the behaviour of generations after date 0 . The young members of each generation, taking prices as given, invest too much in land (over-save) to insure against the bad realisation of uncertainty. The fiscal authority, by decreasing investment in land by young individuals, induces a non trivial change in asset prices. The latter effect induces a reallocation of wealth among members of each generation that is welfare improving. Effectively, individuals invest too much in land because prices are not "set optimally" at the competitive equilibrium.

\section{Debt}

To focus on debt, we demonstrate the constrained suboptimality of equilibrium in a two commodity, two period life-span economy of overlapping generations, where individuals hold public debt and invest in land. Multiple commodities serve the same purpose as life-spans of multiple periods. Perturbations of public debt affect the relative price of commodities that, in turn, induces a reallocation of state-contingent wealth that improves ex-ante welfare. As before, there are no short sales of land at equilibrium.

Each generation consists of a continuum, of mass 1, of initially identical individuals. There are two perishable commodities at each date: 1 and 2. Individuals desire both commodities when old and only commodity 1 when young. Commodity 1 is numéraire and its price is normalized to 1 , whereas the price of commodity 2 is $p$. Individuals receive a non-stochastic endowment, $e_{1}^{y}$, when young, a stochastic endowment of commodity $1, e_{1, s}^{o}$, and a non-stochastic endowment of commodity $2, e_{2}^{o}$, when old. Notation and assumptions about land as before. There is a government that issues debt, $b$, pays interest on debt, $i$, and levies lump-sum taxes, $\tau$. Time commences at $t=0$; we omit the subscript, $t$, that indicates dates, when no ambiguity arises. Notation and assumptions about personal states as before; there is no aggregate risk. 
The decision of an individual is

$$
\begin{aligned}
& \max U=\left[c_{1}^{y}+E\left[u\left(c_{1, s}^{o}\right)\right]+E\left[u\left(c_{2, s}^{o}\right)\right]\right], \\
& \text { s.t } \\
& c_{1}^{y}+b+q y=e_{1}^{y}-\tau, \\
& c_{1, s}^{o}+p c_{2, s}^{o}=e_{1, s}^{o}+p e_{2}^{o}+(f+q) y+(1+i) b ;
\end{aligned}
$$

consumption of commodities 1 and 2 are $c_{1}$ and $c_{2}$ respectively. First order conditions are

$$
\begin{aligned}
\lambda^{y} & =1, \lambda_{s}^{o}=u^{\prime}\left(c_{1, s}^{o}\right)=\frac{u^{\prime}\left(c_{2, s}^{o}\right)}{p}, \\
\frac{1}{1+i} & =\frac{q}{f+q}=E\left[\lambda_{s}^{o}\right] ;
\end{aligned}
$$

$\lambda^{y}$ and $\lambda_{s}^{o}$ are the Lagrange multipliers associated with the budget constraints of young and old individuals respectively.

No arbitrage between land and debt implies

$$
i=\frac{f}{q} \text {. }
$$

There exist groups, $s$, of initial old generations, of size $\pi_{s}$, with preferences $U_{s}^{o}\left(c_{1, s}^{o}, c_{2, s}^{o}\right)=u\left(c_{1, s}^{o}\right)+u\left(c_{2, s}^{o}\right)$ and endowments, holdings of land and debt as all future old generations.

The government issues debt and levies taxes to finance outstanding debt

$$
b_{t}+\tau_{t}=\left(1+i_{t-1}\right) b_{t-1}
$$

For stationarity,

$$
\tau=i b
$$

We compute a robust example to demonstrate the constrained suboptimality of equilibrium; details are presented in the Appendix. An economy is specified by $\left(u, f, e_{1}^{y}, e_{2}^{o}, \ldots, \pi_{s}, \ldots, e_{1, s}^{o}, \ldots\right)$ and fiscal policy by $(\tau, b)$.

At all periods, the government perturbs debt ${ }^{2}$ held by young individuals; in addition, it redistributes wealth, but, only at $t=0$. Subsequently, individuals trade in commodity and land markets. We restrict the analysis to stationary marginal changes of debt.

\footnotetext{
${ }^{2}$ As a consequence, lump-sum taxes have to be adjusted accordingly in order for the government budget to be satisfied.
} 
For $t=0$, and since, then (and only then) the fiscal authority can redistribute revenue, for a Pareto improvement it suffices that

$$
\mathrm{d} U_{0}+E\left[\frac{\mathrm{d} U_{s}^{o}}{\lambda_{s}^{o}}\right]=\left(\frac{1}{1+i} \mathrm{~d} q+\mathrm{d} b+\frac{b}{1+i} \mathrm{~d} i\right)+\left(E\left[\lambda_{s}^{o}\left(e_{2}^{o}-c_{2, s}^{o}\right)\right]\right) \mathrm{d} p>0
$$

Marginal changes of relative prices are

$$
\mathrm{d} p=\frac{1+i}{e_{2}^{o}}\left(\frac{1}{1+i} \mathrm{~d} q+\mathrm{d} b+\frac{b}{1+i} \mathrm{~d} i\right)
$$

To simplify the exposition, define as $z$ the following expression

$$
z=\frac{1}{1+i} \mathrm{~d} q+\mathrm{d} b+\frac{b}{1+i} \mathrm{~d} i
$$

The government can always perturb debt appropriately to determine the sign of $z$. To see this, rewrite (7) as

$$
z=\left(\frac{1}{1+i} \frac{\partial q}{\partial b}+1+\frac{b}{1+i} \frac{\partial i}{\partial b}\right) \mathrm{d} b
$$

and, given the sign of the term in parenthesis, marginal changes of debt determine the sign of $z$.

Substituting (6) and (7) into (5), it follows

$$
\mathrm{d} U_{0}+E\left[\frac{\mathrm{d} U_{s}^{o}}{\lambda_{s}^{o}}\right]=\left(1+\left(E\left[\lambda_{s}^{o}\left(e_{2}^{o}-c_{2, s}^{o}\right)\right]\right) \frac{1+i}{e_{2}^{o}}\right) z>0
$$

The term that multiplies $z$ is positive; a restriction (inequality) that is satisfied at the stationary competitive equilibrium. Marginal changes of debt that induce $z>0$ imply that the sum of perturbed utilities is positive.

Generations $t \geqslant 1$ are better off if and only if

$$
\mathrm{d} U_{t}=\left(-i+\left(E\left[\lambda_{s}^{o}\left(e_{2}^{o}-c_{2, s}^{o}\right)\right]\right) \frac{1+i}{e_{2}^{o}}\right) z>0 .
$$

The term that multiplies $z$ is positive; the second restriction (inequality) that is satisfied at the stationary competitive equilibrium. Since we require $z>0$, marginal changes of debt induce a Pareto improvement.

Remark 1 It is the pecuniary externality induced by $\mathrm{d} p \neq 0$ and trade in the second commodity, $e_{2}^{o} \neq c_{2, s}^{o}$, that drives the constrained suboptimality result. If $\mathrm{d} p=0$ or $e_{2}^{o}=c_{2, s}^{o}$, then the stationary competitive equilibrium is constrained optimal. 


\section{Capital}

Finally, we introduce capital and demonstrate that improving interventions are characterised by higher levels of capital investment relative to the competitive level; the competitive allocation is characterised by under-investment.

The economy is stationary, of overlapping generations with life-spans of two periods. Each generation consists of a continuum, of mass 1, of initially identical individuals. There are two commodities at each date: consumption and labor. Young and old members of each generation are endowed with $\bar{l}$ units of time that they supply inelastically to the market. Shocks affect the individual efficiency of capital investment. Notation and assumptions about land as before. There is a firm that rents capital, hires labor and produces output using a Cobb-Douglas technology: $F(k, l)=k^{a} l^{1-a}$; $k$ is capital and $l$ labor employed. Profit maximisation requires

$$
\begin{aligned}
1+r & =a k^{a-1} l^{1-a}, \\
w & =(1-a) k^{a} l^{-a} ;
\end{aligned}
$$

$(1+r)$ is the real interest rate (factor), and $w$ the real wage. Notation and assumptions about personal states as before; there is no aggregate risk.

The decision of an individual is

$$
\begin{aligned}
& \max U=\left[c^{y}+E\left[u\left(c_{s}^{o}\right)\right]\right], \\
& \text { s.t } \\
& c^{y}+k+q y=w \bar{l}, \\
& c_{s}^{o}=(1+r) \varrho_{s} k+w \bar{l}+(f+q) y ;
\end{aligned}
$$

$c$ is for consumption and $\varrho_{s}$ are shocks to individual capital efficiency; shocks are positive and satisfy the normalisation $E\left[\varrho_{s}\right]=1$. First order conditions are

$$
\begin{aligned}
& \frac{1}{1+r}=E\left[\varrho_{s} u^{\prime}\left(c_{s}^{o}\right)\right], \\
& \frac{q}{f+q}=E\left[u^{\prime}\left(c_{s}^{o}\right)\right] .
\end{aligned}
$$

There is an initial old generation with preferences $U_{0}^{o}\left(c_{0}^{o}\right)=c_{0}^{o}$ and

$$
c_{0}^{o}=F\left(k_{-1}, l\right)-w l+w \bar{l}+f+q,
$$

where $k_{-1}$ is the initial capital stock and $F\left(k_{-1}, l\right)-w l$ are profits of the firm net of capital cost at date 0 . Initial old are endowed with one unit of land and $\bar{l}$ units of time.

We demonstrate the constrained suboptimality of equilibrium with a robust example; as before, details are presented in the Appendix. An economy is specified by $\left(u, f, a, \bar{l}, \ldots, \pi_{s}, \ldots, \varrho_{s}, \ldots\right)$. At all periods, a fiscal authority dictates investment in capital, $k$, by young individuals; in addition, it redistributes wealth, but, only at $t=0$. Subsequently, individuals trade in commodity and land markets. We restrict the analysis to stationary marginal changes of capital. 
To proceed it is useful to demonstrate the following result: for linear-concave utilities and Cobb-Douglas technology, the price of land depends negatively on capital investment:

$$
\frac{\partial q}{\partial k}<0
$$

To see this, consider the first order condition with respect to land and substitute into it the budget constraint of old individuals, firm's first order conditions and market clearing. Differentiating $q$ with respect to $k$, it follows

$$
\frac{\partial q}{\partial k}=\frac{1}{\frac{f}{(f+q)^{2}}-E\left[u^{\prime \prime}\left(c_{s}^{o}\right)\right]} E\left[u^{\prime \prime}\left(c_{s}^{o}\right)\left(\varrho_{s}\left(k \frac{\partial r}{\partial k}+1+r\right)+\bar{l} \frac{\partial w}{\partial k}\right)\right]
$$

$u^{\prime \prime}<0, k(\partial r / \partial k)+1+r>0,(\partial w / \partial k)>0$, from strict concavity, Cobb-Douglas and the first order conditions of the firm, respectively. As a result, $(\partial q / \partial k)<0$.

For $t=0$, and since, then (and only then) the fiscal authority can redistribute revenue, for a Pareto improvement it suffices that

$$
\mathrm{d} c_{0}^{o}+\mathrm{d} U_{0}=\left(\bar{l} \frac{\partial w}{\partial k}\left[\left(\frac{q}{f+q}-\frac{1}{1+r}\right)-\frac{1}{1+r}\right]+\frac{\partial q}{\partial k} \frac{q}{f+q}\right) \mathrm{d} k>0 .
$$

The term that multiplies $\mathrm{d} k$ is positive; a restriction (inequality) that is satisfied at the stationary competitive equilibrium. A policy of higher investment relative to the equilibrium allocation, $\mathrm{d} k>0$, implies that the sum of perturbed utilities is positive.

Generations $t \geqslant 1$ are better off if and only if

$$
\mathrm{d} U_{t}=\left(\bar{l} \frac{\partial w}{\partial k}\left[\left(\frac{q}{f+q}-\frac{1}{1+r}\right)+\frac{r}{1+r}\right]-\frac{\partial q}{\partial k} \frac{f}{f+q}\right) \mathrm{d} k>0 .
$$

We demonstrate that the term that multiplies $\mathrm{d} k$ in (8) is always positive at equilibrium. As a result, only a policy that increases capital investment relative to the competitive level, $\mathrm{d} k>0$, can induce a Pareto improvement.

According to the previous argument, $(\partial q / \partial k)<0$ and $(\partial w / \partial k)>0$. Moreover, $(1+r-(f+q) / q)>0$ is the risk premium between the risky investment in capital and the safe investment in land which is positive at equilibrium. A positive risk premium implies $r>0$. As a result, the term inside the parenthesis in (8) is positive.

Remark 2 It is the pecuniary externality induced by perturbations of labor income of old members of each generation that drives the constrained suboptimality result. In particular, a small increase in $k$ lowers $r$ and increases $w$, scaling down the part of income of old individuals that is stochastic and scaling up one part that is deterministic. Also, a small increase in $k$ lowers $q$, that, in turn, lowers the other part of income that is deterministic. For the parameter values that we specify to compute an equilibrium (see the Appendix), the increase of $w$ dominates and an increase in $k$ induces a Pareto improvement. Finally, if old individuals do not supply labor, then the stationary allocation is constrained optimal. 
Remark 3 Carvajal and Polemarchakis (2011) considered a similar economy where idiosyncratic shocks affect only the productivity of labor of old members of each generation. They gave an example where the competitive allocation is characterized by over-investment in capital. Krebs (2003) considered an infinite horizon economy with heterogenous infinite-lived agents that invest in physical and human capital and idiosyncratic shocks affect only the return to human capital. He argued that a reduction in idiosyncratic risk reduces investment in physical, but increases investment in human capital; the equilibrium is characterised by over-investment in physical capital and under-investment in human capital. Geanakoplos and Kübler (2015) considered a twoperiod economy with heterogenous agents and incomplete markets. They described mechanisms through which, at equilibrium, agents over-borrow.

Open Access This article is distributed under the terms of the Creative Commons Attribution 4.0 International License (http://creativecommons.org/licenses/by/4.0/), which permits unrestricted use, distribution, and reproduction in any medium, provided you give appropriate credit to the original author(s) and the source, provide a link to the Creative Commons license, and indicate if changes were made.

\section{Appendix}

We complete the argument for each of the sections.

\section{Land}

We compute a stationary equilibrium for the economy of section "Land". Fix two personal states, $s \in\{H, L\}, u(c)=\log (c), f>0, e^{o}=0, e^{y}>0, e_{s}^{m}=e^{m}+\epsilon_{s}>$ $0, E\left[\epsilon_{s}\right]=0$.

At a stationary equilibrium

$$
\begin{aligned}
& \frac{q}{f+q} \frac{1}{e^{y}-q y^{y}}=\frac{\pi_{H}}{e_{H}^{m}+(f+q) y^{y}-q y_{H}^{m}}+\frac{\pi_{L}}{e_{L}^{m}+(f+q) y^{y}-q y_{L}^{m}}, \\
& \frac{q}{f+q}=\frac{e_{s}^{m}+(f+q) y^{y}-q y_{s}^{m}}{(f+q) y_{s}^{m}}, \text { and } \\
& y^{y}+\pi_{H} y_{H}^{m}+\pi_{L} y_{L}^{m}=1 .
\end{aligned}
$$

From (10) we solve for middle-aged asset holdings, $y_{s}^{m}$, as

$$
y_{s}^{m}=\frac{e_{s}^{m}+(f+q) y^{y}}{2 q} .
$$

Substituting (12) into (9) to solve for young's asset holdings, we obtain

$$
\begin{aligned}
\frac{q}{f+q} \frac{1}{e^{y}-q y^{y}}= & \frac{\pi_{H}}{e_{H}^{m}+(f+q) y^{y}-q \frac{e_{H}^{m}+(f+q) y^{y}}{2 q}} \\
& +\frac{\pi_{L}}{e_{L}^{m}+(f+q) y^{y}-q \frac{e_{L}^{m}+(f+q) y^{y}}{2 q}} .
\end{aligned}
$$


(13) simplifies as

$$
\begin{aligned}
& 3 q(f+q)\left(y^{y}\right)^{2}+y^{y}\left(q\left(e_{H}^{m}+e_{L}^{m}+2 \Delta\right)-2 e^{y}(f+q)\right) \\
& \quad+\frac{q}{f+q} e_{H}^{m} e_{L}^{m}-2 e^{y} \Delta=0,
\end{aligned}
$$

where $\Delta=\pi_{H} e_{L}^{m}+\pi_{L} e_{H}^{m}$. From (14), we get

$$
\begin{aligned}
y^{y}= & \frac{-\left(q\left(e_{H}^{m}+e_{L}^{m}+2 \Delta\right)-2 e^{y}(f+q)\right)}{6 q(f+q)} \\
& \pm \frac{\sqrt{\left(q\left(e_{H}^{m}+e_{L}^{m}+2 \Delta\right)-2 e^{y}(f+q)\right)^{2}-12 q(f+q)\left(\frac{q}{d+q} e_{H}^{m} e_{L}^{m}-2 e^{y} \Delta\right)}}{6 q(f+q)} .
\end{aligned}
$$

For restrictions on parameters that we specify shortly, the small root of (15) is consistent with negative asset prices and, as a result, we do not consider it. Substitute the big root of (15) into (12) to solve for $y_{s}^{m}$ as a function of $q$. Substituting $y_{s}^{m}$ together with the big root of (15) into (11) to solve for $q$, we obtain

$$
\begin{aligned}
& \frac{-\left(q\left(e_{H}^{m}+e_{L}^{m}+2 \Delta\right)-2 e^{y}(f+q)\right)}{6 q(f+q)} \\
& +\frac{\sqrt{\left(q\left(e_{H}^{m}+e_{L}^{m}+2 \Delta\right)-2 e^{y}(f+q)\right)^{2}-12 q(f+q)\left(\frac{q}{f+q} e_{H}^{m} e_{L}^{m}-2 e^{y} \Delta\right)}}{6 q(f+q)} \\
& +\frac{e^{m}-2 q}{f+3 q}=0 .
\end{aligned}
$$

Equilibrium asset prices are computed from (16). Define the left hand side of (16) as $\Phi(\xi, q)$, where $\xi=\left(f, e^{y}, e^{m}, \pi_{H}, \pi_{L}, \epsilon_{H}, \epsilon_{L}\right)$ and $\pi_{H} \epsilon_{H}+\pi_{L} \epsilon_{L}=0$. Equilibrium requires $\Phi(\xi, q)=0$.

Fix the following economy

$$
\xi^{*}=(1.6,1.05,4,0.2,0.8,3.2,-0.8)
$$

Substituting into (16), and solving numerically, we obtain ${ }^{3}$ :

$$
q=2.04859 \text {. }
$$

Asset holdings of agents are

$$
y^{y}=0.0125451, \quad y_{H}^{m}=1.76848, \quad y_{L}^{m}=0.792198
$$

individuals do not short-sell land.

\footnotetext{
${ }_{3}$ Expression (16) implies two extra roots: $q=-9.19947$ and $q=-0.240055$. Negative asset prices are not candidates for equilibrium.
} 
A stationary equilibrium exists for economies in a neighbourhood of $\xi^{*}$. The argument is as follows. $\Phi(\xi, q)=0$ defines $q$ as a function of $\xi$. The derivative of $\Phi$ with respect to $q$ is nonzero, $(\partial \Phi / \partial q)\left(\xi^{*}, 2.04859\right)=-2.54416 \neq 0$, and the derivative of $\Phi$ with respect to each element of $\xi$ is well-defined. Thus, $(\partial q / \partial \xi)\left(\xi^{*}, 2.04859\right)$ is well-defined.

In the next section we demonstrate the constrained suboptimality of the stationary competitive equilibrium of the $\xi^{*}$ economy and of the respective stationary competitive equilibrium of an economy in a neighbourhood of $\xi^{*}$.

\section{Improving interventions}

A fiscal authority dictates investment in land, $\widetilde{y}_{t}^{y}$, by young individuals and redistributes wealth only at $t=0$. Redistribution is $\left\{\tau_{0, s}^{m}, \tau_{0}^{y}, \tau_{0}^{o}\right\}$, for initial middle-aged, initial young and initial old, respectively. For a Pareto-improvement, it suffices to restrict the actions of the fiscal authority to stationary interventions after the initial date: $\tilde{y}_{t}^{y}=\tilde{y}^{y}>0, t \geqslant 1$.

As argued earlier, from the first order conditions of middle-aged, we compute the equilibrium prices given the alternative allocation of land and redistribution at date 0 . Taking into account the restriction to stationary interventions at $t \geqslant 1$, equilibrium prices at $t=0$ and $t=1$, respectively, are

$$
\widetilde{q}_{0}=\frac{e^{m}+f y^{y}+E\left[\tau_{0, s}^{m}\right]}{2\left(1-\tilde{y}_{0}^{y}\right)-y^{y}}, \quad \text { and } \quad \widetilde{q}_{1}=\frac{e^{m}+f \widetilde{y}_{0}^{y}}{2\left(1-\tilde{y}^{y}\right)-\tilde{y}_{0}^{y}} \text {, }
$$

and at $t \geqslant 2$,

$$
\widetilde{q}=\frac{e^{m}+f \widetilde{y}^{y}}{2\left(1-\widetilde{y}^{y}\right)-\widetilde{y}^{y}}
$$

We compute the marginal change of asset prices, relative to the stationary competitive equilibrium, following a marginal change of policy parameters. Marginal changes in land holdings of the young at $t=0$ are denoted by $\mathrm{d} y_{0}^{y}$, at $t \geqslant 1$ by $\mathrm{d}^{y}$, and marginal changes of transfers at $t=0$ by $\mathrm{d} \tau$. Marginal changes of asset prices at $t=0, t=1$ and $t \geqslant 2$, respectively, are

$$
\begin{aligned}
\mathrm{d} q_{0} & =\frac{2\left(e^{m}+f y^{y}\right)}{\left(2\left(1-y^{y}\right)-y^{y}\right)^{2}} \mathrm{~d} y_{0}^{y}+\frac{1}{2\left(1-y^{y}\right)-y^{y}} E\left[\mathrm{~d} \tau_{0, s}^{m}\right], \\
\mathrm{d} q_{1} & =\frac{e^{m}+2 f\left(1-y^{y}\right)}{\left(2\left(1-y^{y}\right)-y^{y}\right)^{2}} \mathrm{~d} y_{0}^{y}+\frac{2\left(e^{m}+f y^{y}\right)}{\left(2\left(1-y^{y}\right)-y^{y}\right)^{2}} \mathrm{~d} y^{y}, \text { and } \\
\mathrm{d} q & =\frac{3 e^{m}+2 f}{\left(2\left(1-y^{y}\right)-y^{y}\right)^{2}} \mathrm{~d} y^{y} .
\end{aligned}
$$

The derivatives of asset prices with respect to policy parameters (land holdings of young and redistribution), evaluated at the competitive allocation of the $\xi^{*}$ economy or at the competitive allocation of an economy in a neighbourhood of $\xi^{*}$, are positive. 
We compute the marginal changes of utilities relative to the stationary competitive equilibrium, taking into account the restriction to stationary interventions after the initial period. For simplicity, we use the notation $u(c)$, keeping in mind $u(c)=\log (c)$.

The marginal change of utility of a typical generation $t \geqslant 2$ is

$$
\begin{aligned}
\frac{\mathrm{d} U_{t}}{u^{\prime}\left(c^{y}\right)}= & -q \mathrm{~d} y^{y}-y^{y} \mathrm{~d} q+E\left[\frac{u^{\prime}\left(c_{s}^{m}\right)}{u^{\prime}\left(c^{y}\right)}\left((f+q) \mathrm{d} y^{y}+y^{y} \mathrm{~d} q-q \mathrm{~d} y_{s}^{m}-y_{s}^{m} \mathrm{~d} q\right)\right] \\
& +E\left[\frac{u^{\prime}\left(c_{s}^{o}\right)}{u^{\prime}\left(c^{y}\right)}\left((f+q) \mathrm{d} y_{s}^{m}+y_{s}^{m} \mathrm{~d} q\right)\right]
\end{aligned}
$$

Taking into account the first order conditions for an optimum at the stationary competitive equilibrium, (18) simplifies as

$$
\frac{\mathrm{d} U_{t}}{u^{\prime}\left(c^{y}\right)}=-\mathrm{d} q\left(y^{y}\left(1-\frac{q}{f+q}\right)+\left(1-\frac{q}{f+q}\right) E\left[\frac{u^{\prime}\left(c_{s}^{m}\right)}{u^{\prime}\left(c^{y}\right)} y_{s}^{m}\right]\right) .
$$

Following a similar argument for $t=1$,

$$
\frac{\mathrm{d} U_{1}}{u^{\prime}\left(c^{y}\right)}=-\mathrm{d} q\left(-y^{y}\left(\frac{q}{f+q}-\frac{\mathrm{d} q_{1}}{\mathrm{~d} q}\right)+\left(1-\frac{q}{f+q}\right) E\left[\frac{u^{\prime}\left(c_{s}^{m}\right)}{u^{\prime}\left(c^{y}\right)} y_{s}^{m}\right]\right) .
$$

Finally, for $t=0$,

$$
\begin{aligned}
\frac{\mathrm{d} U_{0}}{u^{\prime}\left(c^{y}\right)} & =\mathrm{d} \tau_{0}^{y}+y^{y}\left(\frac{q}{f+q} \mathrm{~d} q_{1}-\mathrm{d} q_{0}\right)-\left(\mathrm{d} q_{1}-\frac{q}{f+q} \mathrm{~d} q\right)\left(E\left[\frac{u^{\prime}\left(c_{s}^{m}\right)}{u^{\prime}\left(c^{y}\right)} y_{s}^{m}\right]\right), \\
\frac{\mathrm{d} U_{0, s}^{m}}{u^{\prime}\left(c_{s}^{m}\right)} & =\mathrm{d} \tau_{0, s}^{m}+y^{y} \mathrm{~d} q_{0}-y_{s}^{m} \mathrm{~d} q_{0}+\frac{q}{f+q} y_{s}^{m} \mathrm{~d} q_{1}, \\
\mathrm{~d} c_{0}^{o} & =\left(1-y^{y}\right) \mathrm{d} q_{0}+\mathrm{d} \tau_{0}^{o},
\end{aligned}
$$

where $\left(1-y^{y}\right)$ are the initial asset holdings of the initial old.

Generations $t \geqslant 2$ are better-off if and only if

$$
\frac{\mathrm{d} U_{t}}{u^{\prime}\left(c^{y}\right)}=-\mathrm{d} q\left(y^{y}\left(1-\frac{q}{f+q}\right)+\left(1-\frac{q}{f+q}\right) E\left[\frac{u^{\prime}\left(c_{s}^{m}\right)}{u^{\prime}\left(c^{y}\right)} y_{s}^{m}\right]\right)>0
$$

The term that multiplies $-\mathrm{d} q$ is positive at any well-defined stationary competitive equilibrium that is characterised by no short sales. Generations $t \geqslant 2$ are better-off if and only if $\mathrm{d} q<0$. According to (17), to achieve that target, the fiscal authority must dictate lower investment in land by young individuals after the initial date: $\mathrm{d} y^{y}<0$. 
For $t=0$, and as we demonstrate at the end of this section, for a Pareto improvement it suffices that

$$
\mathrm{d} c_{0}^{o}+E\left[\frac{\mathrm{d} U_{0, s}^{m}}{u^{\prime}\left(c_{s}^{m}\right)}\right]+\frac{\mathrm{d} U_{0}}{u^{\prime}\left(c^{y}\right)}>0
$$

or, equivalently,

$$
\mathrm{d} q_{1}\left(\frac{q}{f+q}-E\left[\frac{u^{\prime}\left(c_{s}^{m}\right)}{u^{\prime}\left(c^{y}\right)} y_{s}^{m}\right]\right)+\mathrm{d} q \frac{q}{f+q} E\left[\frac{u^{\prime}\left(c_{s}^{m}\right)}{u^{\prime}\left(c^{y}\right)} y_{s}^{m}\right]>0 .
$$

Marginal changes of asset price at $t=0$ cancel out by taking the sum of perturbed utilities across individuals. Also, transfers (redistribution of revenue) add up to zero: $\mathrm{d} \tau_{0}^{o}+\mathrm{d} \tau_{0}^{y}+E\left[\mathrm{~d} \tau_{0, s}^{m}\right]=0$. The term multiplying $\mathrm{d} q_{1}$ is positive at the stationary equilibrium of the $\xi^{*}$ economy:

$$
\frac{q}{f+q}-E\left[\frac{u^{\prime}\left(c_{s}^{m}\right)}{u^{\prime}\left(c^{y}\right)} y_{s}^{m}\right]>0
$$

Since (20) is an inequality, it is satisfied at the corresponding stationary equilibrium of an economy in a neighbourhood of $\xi^{*}$. Moreover, the term multiplying $\mathrm{d} q$ in (19) is always positive at a stationary equilibrium that is characterised by no short sales. Since we require $\mathrm{d} q<0$, a necessary condition for (19) to be satisfied is $\mathrm{d} q_{1}>0$. The next step is to demonstrate that there exists interventions such that (19) is satisfied. To that end, it can be equivalently written as

$$
\mathrm{d} y_{0}^{y}>-\mathrm{d} y^{y}\left(\frac{2\left(e^{m}+f y^{y}\right)}{e^{m}+2 f\left(1-y^{y}\right)}+\frac{3 e^{m}+2 f}{e^{m}+2 f\left(1-y^{y}\right)} \frac{\frac{q}{f+q} E\left[\frac{u^{\prime}\left(c_{s}^{m}\right)}{u^{\prime}\left(c^{y}\right)} y_{s}^{m}\right]}{\frac{q}{f+q}-E\left[\frac{u^{\prime}\left(c_{s}^{m}\right)}{u^{\prime}\left(c^{y}\right)} y_{s}^{m}\right]}\right) \text {. }
$$

To derive (21), we have substituted for $\mathrm{d} q_{1}$ and $d q$ as a function of $\mathrm{d} y_{0}^{y}$ and $\mathrm{d} y^{y}$ from (17). The right hand side of (21) is positive since we require $\mathrm{d} y^{y}<0$ and, also, the term inside the parenthesis is positive at a stationary equilibrium that is characterised by no short sales and satisfies (20). The fiscal authority can perturb investment in land by young individuals at $t=0$ to satisfy (21) and make the sum of perturbed utilities positive. Finally, if (21) is satisfied, then $\mathrm{d} q_{1}>0$.

The generation $t=1$ is better-off if and only if

$$
\frac{\mathrm{d} U_{1}}{u^{\prime}\left(c^{y}\right)}=-\mathrm{d} q\left(-y^{y}\left(\frac{q}{f+q}-\frac{\mathrm{d} q_{1}}{\mathrm{~d} q}\right)+\left(1-\frac{q}{f+q}\right) E\left[\frac{u^{\prime}\left(c_{s}^{m}\right)}{u^{\prime}\left(c^{y}\right)} y_{s}^{m}\right]\right)>0 .
$$


Since we require $\mathrm{d} q<0$, generation $t=1$ is better-off if and only if

$$
\left(1-\frac{q}{f+q}\right) E\left[\frac{u^{\prime}\left(c_{s}^{m}\right)}{u^{\prime}\left(c^{y}\right)} y_{s}^{m}\right]>y^{y}\left(\frac{q}{f+q}-\frac{\mathrm{d} q_{1}}{\mathrm{~d} q}\right) .
$$

To demonstrate that (22) is satisfied, it is convenient to combine (19), the sum of perturbed utilities at $t=0$, and (22) as

$$
\begin{aligned}
& \underbrace{\left(1-\frac{q}{f+q}\right) E\left[\frac{u^{\prime}\left(c_{s}^{m}\right)}{u^{\prime}\left(c^{y}\right)} y_{s}^{m}\right]}_{=A}>\underbrace{y^{y}\left(\frac{q}{f+q}-\frac{\mathrm{d} q_{1}}{\mathrm{~d} q}\right)}_{=B} \\
& >\underbrace{y^{y}\left(\frac{q}{f+q}+\frac{\frac{q}{f+q} E\left[\frac{u^{\prime}\left(c_{s}^{m}\right)}{u^{\prime}\left(c^{y}\right)} y_{s}^{m}\right]}{\frac{q}{f+q}-E\left[\frac{u^{\prime}\left(c_{s}^{m}\right)}{u^{\prime}\left(c^{y}\right)} y_{s}^{m}\right]}\right)}_{=\Gamma} .
\end{aligned}
$$

$A>B$ is identical to (22), while $B>\Gamma$ is equivalent to (19). $A>\Gamma$ at the stationary competitive equilibrium of the $\xi^{*}$ economy. In particular, $A-\Gamma=0.154927$. Since it is an inequality, it is satisfied at the corresponding stationary equilibrium of an economy in a neighbourhood of $\xi^{*}$. The fiscal authority has the discretion to make $B>\Gamma$, as argued before, but also can dictate investment in land such that $B$ can be arbitrarily close to $\Gamma$ : choose $\mathrm{d} y_{0}^{y}$ such that the distance between the left and the right hand side of (21) can be made arbitrarily small. Since $A>\Gamma$, there exist perturbation such that $A>B$. As a result, generation $t=1$ can be made better off.

To complete the argument we demonstrate that everyone in $t=0$ can be made better off by appropriate redistribution. In particular, we compute transfers such that

$$
\mathrm{d} c_{0}^{o}=\frac{\epsilon}{3}>0, \quad \frac{\mathrm{d} U_{0}}{u^{\prime}\left(c^{y}\right)}=\frac{\epsilon}{3}>0, \quad \frac{\mathrm{d} U_{0, s}^{m}}{u^{\prime}\left(c_{s}^{m}\right)}=\frac{\epsilon}{3}>0,
$$

where $\epsilon$ is

$$
\begin{aligned}
\epsilon & =\mathrm{d} c_{0}^{o}+E\left[\frac{\mathrm{d} U_{0, s}^{m}}{u^{\prime}\left(c_{s}^{m}\right)}\right]+\frac{\mathrm{d} U_{0}}{u^{\prime}\left(c^{y}\right)} \\
& =\mathrm{d} q_{1}\left(\frac{q}{f+q}-E\left[\frac{u^{\prime}\left(c_{s}^{m}\right)}{u^{\prime}\left(c^{y}\right)} y_{s}^{m}\right]\right)+\mathrm{d} q \frac{q}{f+q} E\left[\frac{u^{\prime}\left(c_{s}^{m}\right)}{u^{\prime}\left(c^{y}\right)} y_{s}^{m}\right]>0 .
\end{aligned}
$$

Initial middle-aged individuals are better off if

$$
\mathrm{d} \tau_{0, s}^{m}=-y^{y} \mathrm{~d} q_{0}+y_{s}^{m} \mathrm{~d} q_{0}-\frac{q}{f+q} y_{s}^{m} \mathrm{~d} q_{1}+\frac{\epsilon}{3} .
$$


$\mathrm{d} q_{0}$ is a function of aggregate transfers to middle-aged, that is, $E\left(\mathrm{~d} \tau_{0, s}^{m}\right)$. Substituting for $\mathrm{d} q_{0}$ as a function of $E\left(\mathrm{~d} \tau_{0, s}^{m}\right)$ from (17), taking into account asset market clearing, multiplying each side of (23) with $\pi_{s}$ and taking the sum of (23) across middle-aged groups, we pin down $E\left[\mathrm{~d} \tau_{0, s}^{m}\right]$ as

$$
E\left[\mathrm{~d} \tau_{0, s}^{m}\right]=\frac{\left(1-2 y^{y}\right) \frac{2\left(e^{m}+f y^{y}\right)}{\left(2\left(1-y^{y}\right)-y^{y}\right)^{2}} \mathrm{~d} y_{0}^{y}-\frac{q}{f+q}\left(1-y^{y}\right) \mathrm{d} q_{1}+\frac{\epsilon}{3}}{\frac{1-y^{y}}{2\left(1-y^{y}\right)-y^{y}}} .
$$

Substituting (24) into (23), we pin down transfers to each group of initial middle-aged. Initial old are better off if

$$
\mathrm{d} \tau_{0}^{o}=-\mathrm{d} q_{0}\left(1-y^{y}\right)+\frac{\epsilon}{3} .
$$

Initial young are better off if

$$
\mathrm{d} \tau_{0}^{y}=-y^{y}\left(\frac{q}{f+q} \mathrm{~d} q_{1}-\mathrm{d} q_{0}\right)+\left(\mathrm{d} q_{1}-\frac{q}{f+q} \mathrm{~d} q\right)\left(E\left[\frac{u^{\prime}\left(c_{s}^{m}\right)}{u^{\prime}\left(c^{y}\right)} y_{s}^{m}\right]\right)+\frac{\epsilon}{3}
$$

Finally, transfers add up to zero

$$
\mathrm{d} \tau_{0}^{o}+\mathrm{d} \tau_{0}^{y}+E\left[\mathrm{~d} \tau_{0, s}^{m}\right]=\epsilon-\epsilon=0
$$

\section{Debt}

Fix $u(c)=\log (c)$, two personal states, $s \in\{H, L\}, e_{1, s}^{o}=e_{1}^{o}+\epsilon_{s}>0, E\left[\epsilon_{s}\right]=0$, $\epsilon_{s} \neq 0, f>0$ and $e_{2}^{o}>0$.

Combining the first order conditions of consumption and the budget constraints of old individuals, we pin down their consumption demands

$$
\begin{aligned}
c_{1, s}^{o} & =\frac{e_{1, s}^{o}+p e_{2}^{o}+(f+q) y+(1+i) b}{2}, \\
c_{2, s}^{o} & =\frac{e_{1, s}^{o}+p e_{2}^{o}+(f+q) y+(1+i) b}{2 p} .
\end{aligned}
$$

Combining commodity 2 market clearing, $E\left[c_{2, s}^{o}\right]=e_{2}^{o}$, and land market clearing, $y=1$, we obtain

$$
p=\frac{1}{e_{2}^{o}}\left(e_{1}^{o}+f+q+(1+i) b\right)
$$

Substituting for $\lambda_{s}^{o}$ as a function of $c_{1, s}^{o}$ and then into the first order condition of debt, we obtain 


$$
\frac{1}{1+i}=E\left[\frac{1}{\frac{e_{1, s}^{o}+p e_{2}^{o}+(f+q) y+(1+i) b}{2}}\right] .
$$

Substituting (25), the no arbitrage between debt and land, $i=f / q$, and land market clearing into (26), we obtain

$$
\frac{1}{1+i}=E\left[\frac{1}{\frac{1}{2}\left(e_{1, s}^{o}+e_{1}^{o}+2 f\left(1+\frac{1}{i}\right)+2(1+i) b\right)}\right]
$$

the equilibrium interest rate is a function of $b$.

To facilitate computations, fix parameters as

$$
f=0.001, e_{1}^{o}=0.3, \epsilon_{H}=0.25, \epsilon_{L}=-0.25, \pi_{H}=\pi_{L}=0.5, e_{2}^{o}>0 .
$$

$e_{2}^{o}$ cancels out and does not affect the equilibrium interest rate and allocation; this is an artefact of log-utilities. Well-defined stationary equilibria, that is, $0<i<\infty$, that can be improved upon by perturbations of public debt, obtained for $b \in(0,0.65)$; at $b \in(0,0.65)$, stationary equilibria satisfy all required inequalities for a Pareto improvement that were mentioned in the section "Debt". Perturbations of commodity prices, interest rates and land prices follow from (25), (27) and the no-arbitrage between land and debt, respectively. Using (27) and the no-arbitrage between land and debt, we can verify that perturbations of public debt have a non-trivial effect on commodity prices. Finally, following a similar argument as in the previous section, stationary equilibria exist for parameters in a neighbourhood of (28). Since the conditions for a Pareto improvement take the form of inequalities, the constrained suboptimality of the stationary allocation or, equivalently, the existence of Pareto improving debt policies is robust.

Perturbation of utilities are derived using a similar methodology as in the section "Land" of the Appendix; we do not repeat the calculations. Finally, individuals at date 0 can be made better off by appropriate redistribution. The methodology is again similar to the previous section and will not be repeated.

\section{Capital}

We demonstrate the constrained suboptimality of the stationary equilibrium allocation.

Substituting the budget constraints of individuals, land market clearing, $y=1$, labor market clearing, $2 \bar{l}=l$, and the firm's first order conditions into the first order conditions of land and capital, we obtain

$$
\frac{q}{f+q}=E\left[u^{\prime}\left(\varrho_{s} a k^{a}(2 \bar{l})^{1-a}+(1-a) k^{a}(2 \bar{l})^{-a} \bar{l}+f+q\right)\right],
$$




$$
\frac{1}{a k^{a-1}(2 \bar{l})^{(1-a)}}=E\left[\varrho_{s} u^{\prime}\left(\varrho_{s} a k^{a}(2 \bar{l})^{1-a}+(1-a) k^{a}(2 \bar{l})^{-a} \bar{l}+f+q\right)\right] .
$$

From (29), we solve for the equilibrium levels of $k$ and $q$.

Fix the following economy: $u(c)=(1 / \gamma) c^{\gamma}$, three equiprobable states, $\{H, M, L\}$, $\varrho_{H}=2.05, \varrho_{M}=0.9, \varrho_{L}=0.05, a=0.2, \bar{l}=3.6, \gamma=-4$ and $f=0.04$. The equilibrium level of investment is $k=0.03471$, the price of land $q=0.01625$ and the risk premium 0.218829 . The equilibrium satisfies all required inequalities for a Pareto improvement that were mentioned in the section "Capital". As before, stationary equilibria exist in a neighbourhood of the previous parameters values. Since the conditions for a Pareto improvement take the form of inequalities, the constrained suboptimality of the stationary allocation is robust.

Finally, perturbation of utilities are derived using a similar argument as in the section "Land" of the Appendix and will not be repeated. The same applies for redistribution policies at date 0 .

\section{References}

Angeletos, G.M.: Fiscal policy with noncontingent debt and the optimal maturity structure. The Quarterly Journal of Economics 117, 1105-1131 (2002)

Bulow, J., Rogoff, K.: Sovereign debt: is to forgive to forget? The American Economic Review 79, 43-50 (1989)

Carvajal, A., Polemarchakis, H.: Idiosyncratic risk and financial policy. Journal of Economic Theory 146, 1569-1597 (2011)

Cass, D.: On capital overaccumulation in the aggregative, neoclassical model of economic growth: a complete characterization. Journal of Economic Theory 4, 200-223 (1972)

Demange, G.: On optimality in intergenerational risk sharing. Economic Theory 20, 1-28 (2002)

Diamond, P.A.: National debt in a neoclassical growth model. The American Economic Review 55, 1126$1150(1965)$

Diamond, P.A., Geanakoplos, J.D.: Social security investment in equities. American Economic Review 93, 1047-1074 (2003)

Dutta, J., Kapur, S., Orszag, J.M.: A portfolio approach to the optimal funding of pensions. Economics Letters 69, 201-206 (2000)

Geanakoplos, J.D., Kübler, F.: Why is too much leverage bad for the economy? Unpublished manuscript (2015)

Geanakoplos, J.D., Polemarchakis, H.: Existence, regularity and constrained suboptimality of competitive allocations when the asset market is incomplete. In: Heller, W., Starr, R., Starrett, D. (eds.) Uncertainty, Information and Communication: Essays in Honour of K. J. Arrow, vol. 3, pp. 65-95. Cambridge University Press, (1986)

Krebs, T.: Human capital risk and economic growth. Quarterly Journal of Economics 118, 709-744 (2003)

Lucas, R.E., Stokey, N.L.: Optimal fiscal and monetary policy in an economy without capital. Journal of Monetary Economics 12, 55-93 (1983)

Samuelson, P.A.: An exact consumption-loan model of interest with or without the contrivance of money. Journal of Economic Theory 66, 467-482 (1958)

Santos, M.S., Woodford, M.: Asset pricing bubbles. Econometrica 65, 19-57 (1997)

Wilson, C.: Equilibrium in dynamic models with an infinity of agents. Journal of Economic Theory 24, 95-111 (1981) 